\title{
Epidemiology and antimicrobial susceptibility of invasive Escherichia coli infection in neonates from 2012 to 2019 in Xiamen, China
}

\author{
Jidong Lai ${ }^{1,2+}$, Yao Zhu ${ }^{1,2+}$, Lixia Tang ${ }^{1,2}$ and Xinzhu Lin ${ }^{1,2^{*}}$
}

\begin{abstract}
Background: Escherichia coli (E. coli) is one of the important causative pathogens of neonatal invasive infection. The epidemiological and clinical profile of invasive E. coli infection in Chinese newborns is not well characterized.

Methods: Ninety-four infants with invasive E. coli infection were categorized into E. coli early onset disease (EOD) group (onset $\leq 72 \mathrm{~h}$ after birth) $(n=46)$ and E. coli late onset disease (LOD) group (onset $>72 \mathrm{~h})(n=48)$. We compared and analyzed the clinical characteristics and drug sensitivity profile of early-onset and late-onset $E$. coli invasive infection in neonates.

Results: The incidence of E. coli-EOD and E.coli-LOD was $0.45 / 1000$ live births (LBs) and 0.47/1000 LBs, respectively. The incidence of gestational diabetes mellitus, perinatal fever, urinary tract infection, chorioamnionitis, and positive E. coli culture among mothers in the E. coli-EOD group were significantly higher than that in E. coli-LOD group. The incidence of premature birth, low-birth-weight, nosocomial infection, and hospitalization time were significantly higher in the E. coli-LOD group. The main disease in E. coli-EOD group was pneumonia (main clinical manifestation: dyspnea). The main disease in E. coli-LOD group was sepsis (main clinical manifestation: fever). The sensitivity rates of E. coli strains to ampicillin and piperacillin were low (25.00-28.79\%); sensitivity to cephalosporins was also low except ceftazidime (lowest sensitivity rate: $57.14 \%$ ). Sensitivity to compound preparations containing $\beta$-lactamase inhibitors was high, even for extended spectrum $\beta$-lactamase-positive strains (nearly 100\%).

Conclusion: $E$. coli is an important cause of invasive infection of newborns in Xiamen, China. E. coli-EOD was largely attributable to perinatal factors, while E. coli-LOD was largely related to nosocomial infection. Compound preparations containing $\beta$-lactamase inhibitor or carbapenem antibiotics should be preferred for neonatal invasive infection by E. coli.
\end{abstract}

Keywords: Escherichia coli, Early-onset infection, Late-onset infection, Clinical characteristics, Drug resistance, Newborn

\footnotetext{
*Correspondence: xinzhufj@163.com

† Jidong Lai and Yao Zhu contributed equally to this work.

'Department of Neonatology, Women and Children's Hospital, School of Medicine, Xiamen University, No.10 Zhenhai Road, Siming District, Xiamen 361003, Fujian Province, China

${ }^{2}$ Xiamen key laboratory of perinatal-neonatal infection, Xiamen 361003,

Fujian Province, China
}

(c) The Author(s). 2021 Open Access This article is licensed under a Creative Commons Attribution 4.0 International License, which permits use, sharing, adaptation, distribution and reproduction in any medium or format, as long as you give appropriate credit to the original author(s) and the source, provide a link to the Creative Commons licence, and indicate if changes were made. The images or other third party material in this article are included in the article's Creative Commons licence, unless indicated otherwise in a credit line to the material. If material is not included in the article's Creative Commons licence and your intended use is not permitted by statutory regulation or exceeds the permitted use, you will need to obtain permission directly from the copyright holder. To view a copy of this licence, visit http://creativecommons.org/licenses/by/4.0/ The Creative Commons Public Domain Dedication waiver (http://creativecommons.org/publicdomain/zero/1.0/) applies to the data made available in this article, unless otherwise stated in a credit line to the data. 


\section{Background}

According to a meta-analysis, neonatal mortality accounted for $45.1 \%$ of deaths in children under the age of 5 years globally in 2015; of these, approximately 21\% deaths were caused by neonatal infection including pneumonia, sepsis and purulent meningitis [1]. Escherichia coli (E. coli) is a common causative pathogen of neonatal invasive infectious diseases $[2,3]$. According to the time of onset of infection, E. coli disease is categorized into earlyonset $E$. coli disease (E.coli-EOD; onset within 3 days after birth) and late-onset $E$. coli disease (E. coli-LOD; onset within 3-28 days after birth). Neonatal E. coli-EOD is largely caused by prenatal or intrapartum infection (vertical transmission) and typically manifests as pneumonia. $E$. coli-LOD typically presents as sepsis, pneumonia, or meningitis, which is mostly due to environmental or nosocomial bacterial infection $[2,4]$.

There is considerable variability in the incidence of neonatal invasive $E$. coli infection in different geographical areas and countries. In a study of 30 neonatal intensive care units (NICU) in the United Kingdom (UK), the incidence of early-onset $E$. coli sepsis and late-onset $E$. coli sepsis in the period 2005-2014 was 0.12/1000 live births (LBs) 0.33/1000 LBs, respectively [3]. In an Italian study, the incidence of neonatal late-onset $E$. coli sepsis was found to be $0.35 / 1000$ LBs [5]. In China, E. coli is the main causative pathogen of neonatal invasive infection, especially neonatal sepsis [6].

The wide usage of broad-spectrum antibiotics has fueled the emergence of drug-resistant strains of $E$. coli, which poses a great challenge in the treatment of neonatal bacterial infections. Several recent studies have found that E. coli is widely resistant to ampicillin and shows different degrees of resistance to the thirdgeneration cephalosporins $[2,7]$. However, the drug resistance profile of $E$. coli shows considerable interregional variability depending on the local pattern of antibiotic use, which is worthy of further study.

Currently, there is a lack of robust data pertaining to the incidence, clinical characteristics, and drug sensitivity profile of neonatal E. coli invasive infection in China. The purpose of this study was to analyze the clinical characteristics and drug sensitivity profile of early-onset and late-onset $E$. coli invasive infection in China. Our findings may provide a scientific basis for more targeted prevention and control measures.

\section{Methods}

\section{Study population and design}

This study was approved by the Ethics Committee of the Women and Children's Hospital, School of Medicine, Xiamen University (Xiamen, China). We retrospectively reviewed the medical records of 106 infants with invasive E. coli infection who were hospitalized at our department between January 2012 and December 2019.

\section{Inclusion criteria}

Infants with invasive $E$. coli infection including $E$. coli pneumonia, E. coli sepsis, E. coli meningitis, and E. coli abscess.

\section{Exclusion criteria}

1) Asymptomatic patients with positive E. coli culture of the upper airway secretions or body surface secretions; 2) infants with congenital malformations and genetic metabolic diseases; and 3) infants in whom treatment was stopped within $72 \mathrm{~h}$ after birth upon request by the family members.

The study subjects were categorized into colonization group and invasive infection group according to the presence or absence of clinical manifestations. The invasive infection group was further categorized into two groups according to the time of onset of the disease. In the $E$. coli-EOD group $(n=46)$, infection occurred within $72 \mathrm{~h}$ after birth, while in the E. coli-LOD group $(n=48)$, infection occurred within 3-28 days after birth (Fig. 1). Based on the resistance of $E$. coli to extended spectrum $\beta$-lactamase (ESBL), the invasive infection group was further categorized into ESBL-positive group and ESBLnegative group.

\section{Study data set}

Demographic and clinical data of subjects were collected using a specially designed questionnaire. The data collected included basic information (sex, gestational age, birth weight, age at admission, age at onset), prenatal conditions [premature rupture of membranes (PROM), meconium-stained amniotic fluid (MSAF), intrauterine infection, prenatal hormone use, gestational diabetes mellitus (GDM)], spectrum of disease, complications, drug sensitivity results, treatment, and outcomes.

\section{E.coli culture and antimicrobial susceptibility testing}

Prior to administering antibiotics, samples of tracheal secretion, peripheral blood, cerebrospinal fluid, pus, or urine were cultured in Columbia blood agar plate (Beiruite Biotechnology Co. Ltd., Zhengzhou, China) for bacterial identification and determination of the E. coli strains using the American PHOENIX100 bacterial identification system (Becton and Dickinson Company, Franklin Lake, NJ, USA). After identification, E. coli strains were isolated and drug sensitivity test was carried out by disk diffusion method. All disks were purchased from the Mast Co. UK. Antibiotic sensitivity testing was carried out as recommended by the Clinical and Laboratory Standards Institute (CLSI), United States. E. coli ATCC 25922 was used for quality control of the test 


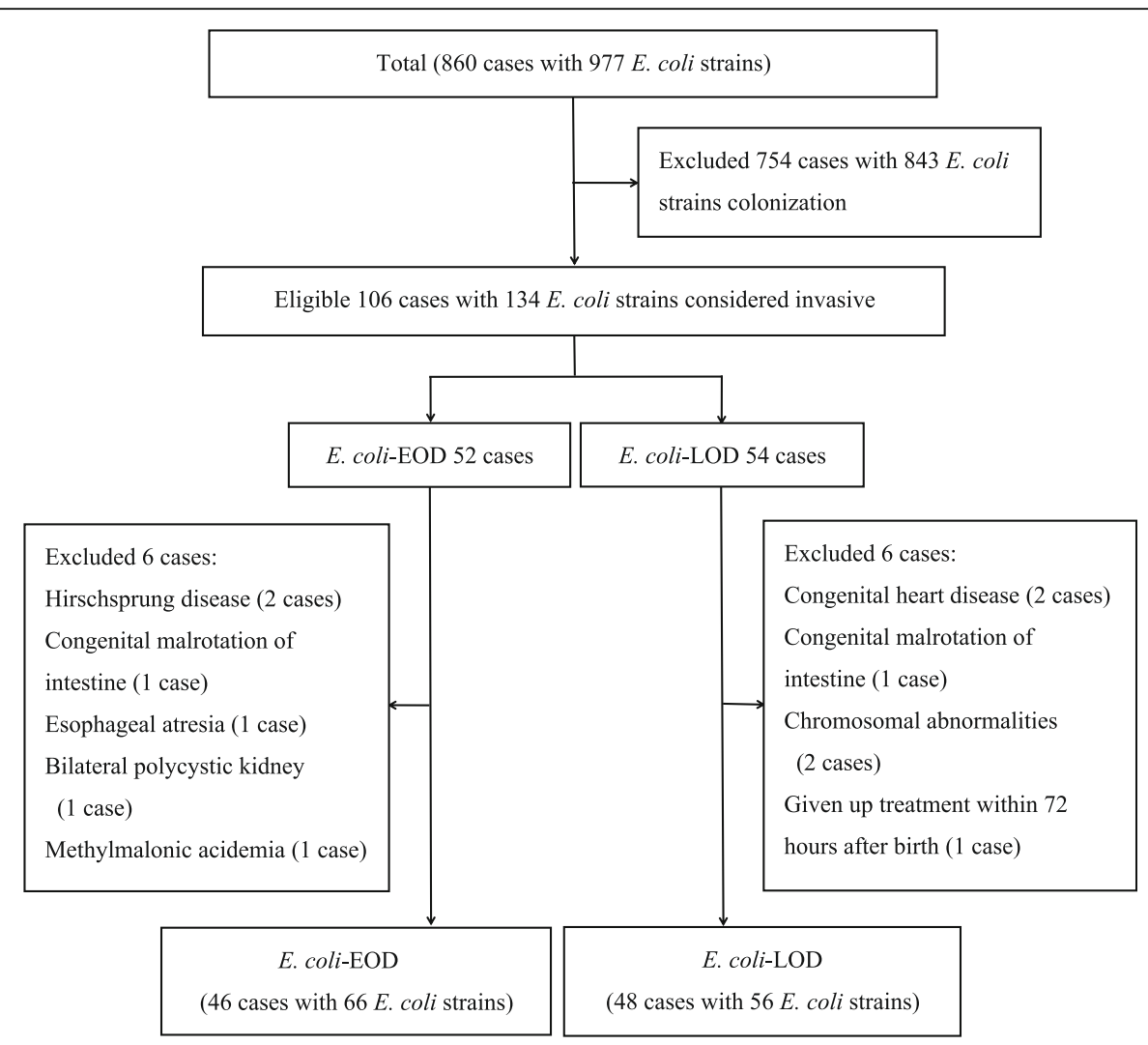

E. coli: Escherichia coli; E. coli-EOD: early onset E. coli disease; E. coli-LOD: late onset E. coli disease

Fig. 1 Schematic illustration of the study population and patient-selection criteria. E. coli: Escherichia coli; E. coli-EOD: early onset E. coli disease; E. coli-LOD: late onset E. coli disease

provided by the clinical laboratory center of the Chinese Ministry of health. If the diameter of the inhibition zone around the cefotaxime/clavulanic acid and ceftazidime/ clavulanic acid disks was at least $5 \mathrm{~mm}$ greater compared to disks without clavulanic acid, the strain was considered as ESBL-producer.

\section{Study definitions/diagnostic criteria \\ $E$. coli invasive infection}

Positive E. coli culture from tracheal secretions (collected by endotracheal intubation within $30 \mathrm{~min}$ after admission and prior to antibiotic use), blood, pus, or urine collected from infants aged 1-28 days with symptoms and diagnosis of pneumonia (shortness of breath, exudative shadows in X-ray images, positive $E$. coli culture from tracheal secretions), sepsis, meningitis, urinary infection (fever, abnormal urine routine, positive E. coli culture from urine) or skin abscess (fever, swelling, and tenderness, positive E. coli culture from pus). E. coli invasive infection was diagnosed according to the Practical Neonatology (5th ed.) and the Chinese neonatal sepsis guidelines $[8,9]$.

\section{Complications of invasive E. coli infection}

Based on the diagnosis of invasive $E$. coli infection, occurrence of the following complications was defined as severe E. coli infection: 1) Acute respiratory distress syndrome (ARDS) according to the Montreux Standard (2017 Edition) [10]; 2) Pulmonary hemorrhage according to Practical Neonatology (5th ed.) [8]; 3) Septic shock in line with the guidelines for septic shock in children [11]; 4) Persistent pulmonary hypertension of the newborn (PPHN) consistent with the diagnostic criteria of neonatal pulmonary hypertension [12]; 5) Necrotizing enterocolitis (NEC) according to Practical Neonatology (5th ed.) [8].

\section{Statistical analyses}

SPSS Statistics for Windows, Version 25.0 (IBM Corp., Armonk, NY, USA) was used for statistical analysis. Distribution of the data was assessed for normality using the Kolmogorov-Smirnov test. Normally distributed continuous variables are presented as mean and standard deviation, and between-group differences assessed using the Student's $t$ test. Categorical variables are presented as frequency and percentage and between-group 
differences assessed using the Chi-squared or Fisher's Exact test. Non-normally distributed continuous variables are presented as median and interquartile range [M (P25-P75)], and between-group differences assessed using the Mann Whitney $U$ test. $P$ values $<0.05$ were considered indicative of statistical significance.

\section{Results}

Frequency of $E$. coli colonization and invasive infection in newborns

During the study reference period, a total of 115,538 live births (LBs) occurred in our hospital, of which 36,310 newborns were hospitalized in our department. Among these, 977 E. coli strains were isolated from 860 newborns. A total of 754 cases with 843 strains had no clinical manifestations and were considered as cases of $E$. coli colonization, while 106 cases with 134 strains were considered as cases of $E$. coli infection. Of these, 12 cases were excluded based on our study-selection criteria. Thus, 94 infants with $122 \mathrm{E}$. coli strains isolated from various specimens were included in this study; of these, 46 were categorized as E. coli-EOD cases and 48 as $E$. coli-EOD cases. The detection rate of $E$. coli from newborns at our hospital was 7.44/1000 LBs (860/115538) and 23.68/1000 neonatal admissions (NAs) (860/36310); the incidence of neonatal $E$. coli infection was $0.92 / 1000$ LBs (106/115538) and 2.92/1000 NAs (106/36310). The incidence of neonatal $E$. coli-EOD was $0.45 / 1000 \mathrm{LBs}$ (52/115538) and 1.43/1000 NAs (52/36310), while the incidence of neonatal $E$. coli-LOD was $0.47 / 1000 \mathrm{LBs}$ (54/115538) and 1.49/1000 NAs (54/36310). The incidence of $E$. coli early-onset sepsis was $0.16 / 1000$ LBs (19/115538) and $0.52 / 1000$ NAs (19/36310), while the incidence of $E$. coli late-onset sepsis was $0.25 / 1000$ LBs (29/115538) and 0.80/1000 NAs (29/36310).

The incidence of $E$. coli-EOD and $E$. coli-LOD in newborns from 2012 to 2019 is shown in Fig. 2. The incidence of $E$. coli-EOD showed a downward trend, gradually decreasing from $0.69 / 1000$ LBs in 2012 to $0.19 / 1000$ LBs in 2019. The lowest incidence of $E$. coliLOD was in $2012(0.17 / 1000 \mathrm{LBs})$, while the highest incidence was in 2019 (0.70/1000 LBs). The annual incidence in the intervening years showed no major changes and fluctuated within the range of $0.28-0.48 / 1000$ LBs.

\section{Comparison of clinical features between $E$. coli-EOD group and E. coli-LOD group}

The average age at onset was $0.50(0.20,0.88) \mathrm{h}$ in the $E$. coli-EOD group and $13.52(7.75,18.50) \mathrm{d}$ in the E. coliLOD group. In the $E$. coli-EOD group, all cases had onset within $24 \mathrm{~h}$ after birth; 39 cases (84.78\%) had onset within $2 \mathrm{~h}$ after birth. In terms of maternal factors, there were significant differences between the two groups with respect to the incidence of prenatal hormone usage, gestational diabetes mellitus (GDM), intrapartum temperature $\geq 37.5^{\circ} \mathrm{C}$, gestational vaginitis, gestational bacteriuria, chorioamnionitis, and positive E. coli culture in placental swab or cervical secretions. In terms of newborns, there were significant differences with respect to gestational age, birth weight, length of hospital stay, incidence of preterm birth, low-birth-weight, meconiumstained amniotic fluid (MSAF), breastfeeding, mechanical ventilation, dyspnea, fever, and nosocomial infection. There were no significant between-group differences with respect to the other clinical features (Table 1).

\section{Comparison of disease spectrum and complications between $E$. coli-EOD group and $E$. coli-LOD group}

The distribution of the disease spectrum of $E$. coli invasive infection was as follows: 1$)$ E. coli-EOD group: 30 cases of pneumonia, 10 cases of sepsis, 3 cases of pneumonia+sepsis, 1 case of pneumonia+sepsis+purulent meningitis, 5 cases of sepsis+purulent meningitis; 2) $E$. coli-LOD group: 14 cases of pneumonia, 18 cases of

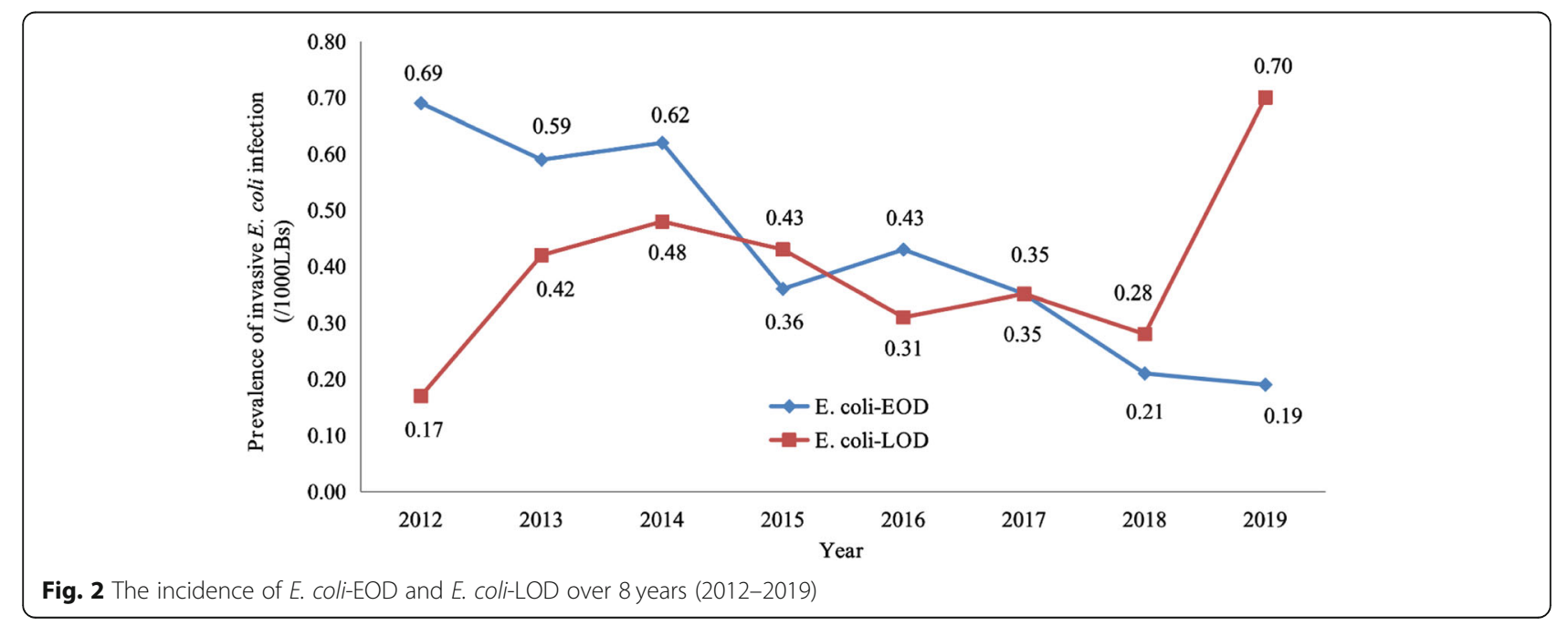


Table 1 Comparison of clinical features between E. coli-EOD group and E. coli-LOD group

\begin{tabular}{|c|c|c|c|c|}
\hline Characteristics & $\begin{array}{l}\text { E. coli-EOD } \\
(n=46)\end{array}$ & $\begin{array}{l}\text { E. coli-LOD } \\
(n=48)\end{array}$ & $x^{2 / t / z}$ value & $P$ \\
\hline \multicolumn{5}{|l|}{ Maternal } \\
\hline \multicolumn{5}{|l|}{ Age, n (\%) } \\
\hline$<20$ years & $2(4.35)$ & $1(2.08)$ & 0.001 & 0.970 \\
\hline$\geq 35$ years & $4(8.70)$ & $8(16.67)$ & 1.34 & 0.247 \\
\hline Regular antenatal screening, $\mathrm{n}(\%)$ & $38(82.61)$ & $41(85.42)$ & 0.138 & 0.710 \\
\hline Cesarean section, n (\%) & $20(43.48)$ & $14(29.17)$ & 2.081 & 0.155 \\
\hline Prenatal hormone usage, n (\%) & $4(8.70)$ & $14(29.17)$ & 5.362 & 0.020 \\
\hline PROM, n (\%) & $8(17.39)$ & $7(14.58)$ & 0.138 & 0.710 \\
\hline GDM, n (\%) & $17(36.96)$ & $4(8.33)$ & 11.091 & 0.001 \\
\hline Intrapartum temperature $\geq 37.5^{\circ} \mathrm{C}, \mathrm{n}(\%)$ & $24(52.17)$ & $1(2.08)$ & 30.189 & 0.000 \\
\hline Gestational vaginitis, n (\%) & $10(21.74)$ & $2(4.17)$ & 6.513 & 0.011 \\
\hline Gestational bacteriuria, n (\%) & $7(15.22)$ & $0(0.00)$ & 5.839 & 0.016 \\
\hline Chorioamnionitis, n (\%) & $28(60.87)$ & $9(18.75)$ & 17.459 & 0.000 \\
\hline Positive E. coli culture in placental swab or cervical secretions, n (\%) & $21(45.65)$ & $1(2.08)$ & 24.873 & 0.000 \\
\hline \multicolumn{5}{|l|}{ Neonatal } \\
\hline Gender (case, male / female) & $30 / 16$ & $31 / 17$ & 0.021 & 0.880 \\
\hline Gestational age, median (IQR), weeks & $39.8(39,40.7)$ & $37.1(32.73,39.28)$ & 4.253 & 0.000 \\
\hline Preterm, n (\%) & $4(8.70)$ & $20(41.67)$ & 13.433 & 0.000 \\
\hline Birth weight, median (IQR), grams & $3400(2983,3663)$ & $2875(1765,3375)$ & 3.138 & 0.002 \\
\hline Low birth weight, n (\%) & $4(8.70)$ & $17(35.42)$ & 9.667 & 0.002 \\
\hline Small for gestational age, $\mathrm{n}(\%)$ & $0(0.00)$ & $2(4.17)$ & - & $0.495^{\mathrm{a}}$ \\
\hline Asphyxia, n (\%) & $3(6.52)$ & $6(12.5)$ & 0.402 & 0.526 \\
\hline MSAF, n (\%) & $26(56.52)$ & $1(2.08)$ & 34.002 & 0.000 \\
\hline Breast-feeding, n (\%) & $40(86.96)$ & $32(66.67)$ & 5.394 & 0.022 \\
\hline Mechanical ventilation, n (\%) & $25(54.35)$ & $7(14.58)$ & 16.542 & 0.000 \\
\hline Duration of mechanical ventilation, median (IQR), days & $3.0(1.5,4.5)$ & $5.0(3.0,10.0)$ & 0.754 & 0.456 \\
\hline Shortness of breath, $\mathrm{n}(\%)$ & $38(82.61)$ & $16(33.33)$ & 23.330 & 0.000 \\
\hline Fever, n (\%) & $2(4.35)$ & $26(54.17)$ & 27.880 & 0.000 \\
\hline Convulsions, n (\%) & $2(4.35)$ & $2(4.17)$ & 0.000 & 1.000 \\
\hline Poor response, $\mathrm{n}(\%)$ & $3(6.52)$ & $3(6.25)$ & 0.000 & 1.000 \\
\hline Jaundice, n (\%) & $0(0.00)$ & $1(2.08)$ & - & $1.000^{\mathrm{a}}$ \\
\hline Nosocomial infection, n (\%) & $0(0.00)$ & $18(37.50)$ & 21.340 & 0.000 \\
\hline Duration of UVC, mean $\pm S D$, days & $4.00 \pm 1.79$ & $6.11 \pm 3.14$ & 1.483 & 0.162 \\
\hline Duration of PICC, median (IQR), days & $30.00(10.50,67.00)$ & $28.00(17.00,52.50)$ & 0.153 & 0.881 \\
\hline Length of hospitalization, median (IQR), days & $13.5(8,16)$ & $16(14,30)$ & 2.794 & 0.005 \\
\hline Mortality, n (\%) & $3(6.52)$ & $2(5.32)$ & 0.002 & 0.961 \\
\hline
\end{tabular}

PROM premature rupture of membranes, GDM gestational diabetes mellitus, MSAF meconium-stained amniotic fluid, UVC umbilical vein catheterization, PICC peripherally inserted central catheter

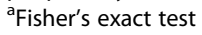

sepsis, 4 cases of urinary tract infection, 3 cases of skin abscess, 2 cases of pneumonia+sepsis, 2 cases of pneumonia+sepsis+purulent meningitis, 5 cases of sepsis+purulent meningitis, 1 case of sepsis+urinary tract infection, and 1 case of sepsis+skin abscess.
There was a significant between-group difference with respect to the incidence of pneumonia and sepsis. There were significant between-group differences with respect to the incidence of ARDS, pulmonary hemorrhage, septic shock, and PPHN (Table 2). 
Table 2 Disease spectrum and complications in the E. coli-EOD and E. coli-LOD groups

\begin{tabular}{|c|c|c|c|c|}
\hline Disease & $\begin{array}{l}\text { E. coli-EOD } \\
(n=46)\end{array}$ & $\begin{array}{l}\text { E. coli-LOD } \\
(n=48)\end{array}$ & $x^{2}$ values & $P$ \\
\hline Pneumonia, n (\%) & $34(73.91)$ & $18(37.50)$ & 12.600 & 0.000 \\
\hline Sepsis, n (\%) & $19(41.30)$ & $29(60.42)$ & 5.112 & 0.021 \\
\hline Purulent meningitis, n (\%) & $6(13.04)$ & $7(14.58)$ & 0.050 & 0.831 \\
\hline Urinary tract infection, n (\%) & $0(0.00)$ & $5(10.42)$ & - & $0.060^{\mathrm{a}}$ \\
\hline Skin abscess, n (\%) & $0(0.00)$ & $4(8.33)$ & - & $0.121^{\mathrm{a}}$ \\
\hline ARDS,n (\%) & $15(32.61)$ & $2(4.17)$ & 12.831 & 0.000 \\
\hline Pulmonary hemorrhage, n (\%) & $10(21.74)$ & $1(2.08)$ & 8.782 & 0.003 \\
\hline Septic shock, n (\%) & $11(23.91)$ & $2(4.17)$ & 7.690 & 0.006 \\
\hline PPHN, n (\%) & $5(10.87)$ & $0(0)$ & - & $0.030^{\mathrm{a}}$ \\
\hline NEC, n (\%) & $1(2.17)$ & $3(6.25)$ & 0.219 & $0.640^{\mathrm{a}}$ \\
\hline
\end{tabular}

ARDS acute respiratory distress syndrome, PPHN persistent pulmonary hypertension of the newborn, NEC necrotizing enterocolitis

${ }^{\text {a }}$ Fisher's exact test

Treatment and outcomes of E. coli-EOD group and E. coliLOD group

In this study, 61 cases $(64.89 \%)$ were treated with piperacillin tazobactam, 24 cases (25.53\%) with cefoperazone sulbactam, and 9 cases $(9.57 \%)$ with meropenem.

In the $E$. coli-EOD group, the cure rate was $93.48 \%$ $(43 / 46)$ and the mortality rate was $6.52 \%$ (3/46). All fatal cases were diagnosed as pneumonia+sepsis and had complications of ARDS, pulmonary hemorrhage, PPHN, and/or septic shock; in all cases, death occurred within $12 \mathrm{~h}$ after onset. In the $E$. coli-LOD group, the cure rate was $95.83 \%$ (46/48) and the mortality rate was $4.16 \%(2 /$ 48). All fatal cases were diagnosed as sepsis and had complications of septic shock; in all cases, death occurred within $24 \mathrm{~h}$ after onset. The overall mortality rate was $5.32 \%$ (5/94). There was no significant betweengroup difference with respect to mortality $(P=0.961)$.

All 13 cases of purulent meningitis were cured (cure rate: $100 \%)$. The findings of plain and contrast-enhanced MRI of brain were consistent with purulent meningitis; these included 2 cases of ependymitis and 1 case of subarachnoid hemorrhage which resolved one month after discharge.

\section{Antibiotic sensitivity profile in the colonization group and invasive infection group}

During the study reference period, 843 strains of $E$. coli cultured from all hospitalized infants in our hospital were considered cases of colonization; these included 592 strains cultured from sputum, 28 strains from endotracheal secretions, 172 strains from gastric secretion, 4 strains from blood, 5 strains from urine, 19 strains from eye secretion, and 23 strains from umbilical secretion. A total of $122 \mathrm{E}$. coli strains were cultured from patients with a diagnosis of invasive infection; these included 66 strains in the EOD group (7 strains from gastric secretion, 34 strains from endotracheal secretion, 19 strains from blood, and 6 strains from the cerebrospinal fluid) and 56 strains in the LOD group (10 strains from endotracheal secretion, 29 strains from blood, 5 strains from urine, 7 strains from CSF, 4 strains from pus, and 1 strain from peripherally inserted central catheter). The positivity rates of ESBL in E. coli-EOD group and E. coliLOD group were $25.76 \%$ (17/66) and $32.14 \%$ (18/56), respectively, with no significant between-group difference ( $\left.\chi^{2}=0.604, P=0.437\right)$. It should be noted that ESBL of $E$. coli was negative in all the 5 patients who died.

Sensitivity to cephalosporins (including cefazolin, ceftazidime, cefotaxime, and cefepime) and aztreonam was lower in the colonization group compared with the invasive infection group. The sensitivity rates of cefepime and amoxicillin/clavulanic acid in the EOD group were higher than those in the colonization group and LOD group $(P=0.023$ and 0.021 , respectively); there was no significant difference with respect to sensitivity to other antibiotics. None of the strains in either group were resistant to amikacin, imipenem, or meropenem.

Compared with the ESBL-negative group, the antibiotic sensitivity rate in the ESBL-positive group was lower, except for compound preparation of $\beta$-lactamase inhibitors (ampicillin/sulbactam, cefoperazone/sulbactam and piperacillin/tazobactam). None of the strains in the ESBL-positive group were resistant to amikacin, imipenem, or meropenem (Tables 3 and 4 ).

\section{Discussion}

In this study, the incidence of $E$. coli invasive infection was $0.92 / 1000 \mathrm{LBs}$ and 2.92/1000 NAs. The incidence of E. coli-EOD was $0.45 / 1000 \mathrm{LBs}$ and $1.43 / 1000 \mathrm{NAs}$, while the incidence of $E$. coli-LOD was $0.47 / 1000 \mathrm{LBs}$ and $1.49 / 1000$ NAs. The incidence of $E$. coli early-onset sepsis was $0.16 / 1000 \mathrm{LBs}$ and $0.52 / 1000 \mathrm{NAs}$, while the incidence of $E$. coli late-onset sepsis was $0.25 / 1000 \mathrm{LBs}$ and $0.80 / 1000$ NAs. There is some variability in the 
Table 3 Antibiotic sensitivity profile of Escherichia coli in the colonization group and invasive infection group [\% ( $n / \mathrm{N})]$

\begin{tabular}{|c|c|c|c|c|c|c|}
\hline \multirow[t]{2}{*}{ Antibiotic } & & \multirow{2}{*}{$\begin{array}{l}\text { Colonization } \\
\text { group } \\
(n=843)\end{array}$} & \multicolumn{2}{|c|}{ Invasive infection group } & \multirow{2}{*}{$\begin{array}{l}\mathrm{X}^{2} \\
\text { values }\end{array}$} & \multirow[t]{2}{*}{$P$} \\
\hline & & & $\begin{array}{l}\text { E. coli-EOD } \\
(n=66)\end{array}$ & $\begin{array}{l}\text { E. coli-LOD } \\
(n=56)\end{array}$ & & \\
\hline \multirow[t]{6}{*}{$\beta$-lactams } & Ampicillin & $23.49(198 / 843)$ & $28.79(19 / 66)$ & $25.00(14 / 56)$ & 0.981 & 0.612 \\
\hline & Piperacillin & $23.84(201 / 843)$ & $28.79(19 / 66)$ & $26.79(15 / 56)$ & 1.000 & 0.610 \\
\hline & Cefazolin & $46.26(390 / 843)$ & $66.67(44 / 66)$ & $57.14(32 / 56)$ & 12.073 & 0.002 \\
\hline & Ceftazidime & $79.48(670 / 843)$ & $95.45(63 / 66)$ & $91.07(51 / 56)$ & 14.024 & 0.001 \\
\hline & Cefotaxime & $58.24(491 / 843)$ & $86.36(57 / 66)$ & $73.21(41 / 56)$ & 24.063 & 0.000 \\
\hline & Cefepime & $61.92(522 / 843)$ & $87.88(58 / 66)$ & $71.43(40 / 56)$ & 19.290 & 0.000 \\
\hline \multirow[t]{4}{*}{ Compound preparations of $\beta$-lactam inhibitors } & Amoxicillin/clavulanic acid & $70.23(592 / 843)$ & $89.39(59 / 66)$ & $73.21(41 / 56)$ & 11.148 & 0.004 \\
\hline & Ampicillin/sulbactam & $47.57(401 / 843)$ & $50.00(33 / 66)$ & $55.36(31 / 56)$ & 1.370 & 0.501 \\
\hline & Cefoperazone /sulbactam & $100.00(843 / 843)$ & $100.00(66 / 66)$ & $98.21(55 / 56)$ & - & - \\
\hline & Piperacillin/tazobactam & $95.14(802 / 843)$ & $100.00(66 / 66)$ & $94.64(53 / 56)$ & 3.412 & 0.184 \\
\hline \multirow[t]{2}{*}{ Carbapenems } & Imipenem & $100.00(843 / 843)$ & $100.00(66 / 66)$ & $100.00(56 / 56)$ & - & - \\
\hline & Meropenem & $100.00(843 / 843)$ & $100.00(66 / 66)$ & $100.00(56 / 56)$ & - & - \\
\hline \multirow[t]{2}{*}{ Quinolones } & Levofloxacin & $74.61(629 / 843)$ & $68.18(45 / 66)$ & $67.86(38 / 56)$ & 2.392 & 0.303 \\
\hline & Ciprofloxacin & $69.75(588 / 843)$ & $65.15(43 / 66)$ & $62.50(35 / 56)$ & 1.791 & 0.412 \\
\hline \multirow[t]{2}{*}{ Aminoglycosides } & Gentamicin & $72.84(614 / 843)$ & $78.79(52 / 66)$ & $83.93(47 / 56)$ & 4.230 & 0.124 \\
\hline & Amikacin & $100.00(843 / 843)$ & $100.00(66 / 66)$ & $100.00(56 / 56)$ & - & - \\
\hline Sulfonamides & Compound sulfamethoxazole & $52.31(441 / 843)$ & $51.52(34 / 66)$ & $55.36(31 / 56)$ & 0.217 & 0.892 \\
\hline Other antibiotics & Aztreonam & $69.51(586 / 843)$ & $93.94(62 / 66)$ & $83.93(47 / 56)$ & 28.223 & 0.000 \\
\hline
\end{tabular}

Table 4 Antibiotic sensitivity of infants with ESBL-positive and ESBL-negative Escherichia coli invasive infection [\% ( $n / \mathrm{N})]$

\begin{tabular}{|c|c|c|c|c|c|}
\hline Antibiotic & & $\begin{array}{l}\text { ESBL positive group }(n= \\
35)\end{array}$ & $\begin{array}{l}\text { ESBL negative group }(n= \\
87 \text { ) }\end{array}$ & $\begin{array}{l}x^{2} \\
\text { values }\end{array}$ & $P$ \\
\hline \multirow[t]{6}{*}{$\beta$-lactams } & Ampicillin & $2.86(1 / 35)$ & $36.78(32 / 87)$ & 14.557 & 0.000 \\
\hline & Piperacillin & $8.57(3 / 35)$ & $35.63(31 / 87)$ & 9.092 & 0.003 \\
\hline & Cefazolin & $11.43(4 / 35)$ & $82.76(72 / 87)$ & 54.066 & 0.000 \\
\hline & Ceftazidime & $80.00(28 / 35)$ & $98.85(86 / 87)$ & 11.561 & 0.001 \\
\hline & Cefotaxime & $37.14(13 / 35)$ & $97.70(85 / 87)$ & 57.924 & 0.000 \\
\hline & Cefepime & $34.29(12 / 35)$ & $98.85(86 / 87)$ & 65.842 & 0.000 \\
\hline \multirow{4}{*}{$\begin{array}{l}\text { Compound preparations of } \beta \text {-lactam } \\
\text { inhibitors }\end{array}$} & Amoxicillin/clavulanic acid & $57.14(20 / 35)$ & $91.95(80 / 87)$ & 20.463 & 0.000 \\
\hline & Ampicillin/sulbactam & $40.00(14 / 35)$ & $57.47(50 / 87)$ & 3.055 & 0.080 \\
\hline & Cefoperazone/sulbactam & $97.14(34 / 35)$ & $100.00(87 / 87)$ & - & $0.287^{\mathrm{a}}$ \\
\hline & Piperacillin/tazobactam & $94.29(33 / 35)$ & $100.00(87 / 87)$ & - & $0.081^{\mathrm{a}}$ \\
\hline \multirow[t]{2}{*}{ Carbapenems } & Imipenem & $100.00(35 / 35)$ & $100.00(87 / 87)$ & - & - \\
\hline & Meropenem & $100.00(35 / 35)$ & $100.00(87 / 87)$ & - & - \\
\hline \multirow[t]{2}{*}{ Quinolones } & Levofloxacin & $54.29(19 / 35)$ & $73.56(64 / 87)$ & 4.265 & 0.039 \\
\hline & Ciprofloxacin & $48.57(17 / 35)$ & $70.11(61 / 87)$ & 5.024 & 0.025 \\
\hline \multirow[t]{2}{*}{ Aminoglycosides } & Gentamicin & $60.00(21 / 35)$ & $89.66(78 / 87)$ & 14.348 & 0.000 \\
\hline & Amikacin & $100.00(35 / 35)$ & $100.00(87 / 87)$ & - & - \\
\hline Sulfonamides & $\begin{array}{l}\text { Compound } \\
\text { sulfamethoxazole }\end{array}$ & $28.57(10 / 35)$ & $63.22(55 / 87)$ & 12.036 & 0.001 \\
\hline Other antibiotics & Aztreonam & $65.71(23 / 35)$ & $98.85(86 / 87)$ & 25.411 & 0.000 \\
\hline
\end{tabular}


incidence rates of neonatal invasive $E$. coli infection in different countries or regions. In a single-center study conducted in Spain spanning the past 20 years, the incidence of neonatal $E$. coli early-onset sepsis was 0.69 / 1000 LBs [13]. In a study of 21 neonatal care centers in Israel from 2010 to 2015, the incidence of $E$. coli earlyonset infection was $0.2 / 1000$ LBs [14]. In a study conducted at a tertiary hospital in India, the rate of neonatal sepsis with blood culture positivity was $6.2 \%$, of which $E$. coli accounted for $14 \%$ [15]. In a study conducted across 25 tertiary hospitals in China from 2015 to 2018, the incidence of neonatal early-onset sepsis caused by $E$. coli in preterm infants younger than 34 weeks of gestation was 2.36/1000 LBs [6]. In recent years, E. coli has replaced group B streptococcus as the most common causative pathogen of neonatal purulent meningitis in Taiwan [16]. Our study also found a downward trend in the incidence of neonatal $E$. coli-EOD over successive years, and the condition often occurred in term infants (up to 91\%). However, the incidence of neonatal E. coliLOD showed no significant change over the years except for a peak in 2019. This phenomenon may be attributable to several factors: 1) The rate of antibiotic usage in mothers in our hospital was high. For example, from 2010 to 2015, the antibiotic use rate of mothers with newborns suffering from early-onset sepsis increased to $38 \%$ [17]. Prophylactic use of cefoxitin sodium was more commonly used in cases of threatened preterm labor, which largely eliminated $E$. coli colonization and reduced the vertical transmission from mothers to newborns. 2) Neonatal E. coli-LOD is often caused by nosocomial infection, which usually occurs in premature infants or low-birth-weight infants. The peak in the incidence of $E$. coli-LOD in 2019 was related to more premature births and infants with critical diseases, as well as the increase in invasive operations.

Our analysis revealed that the occurrence of E. coliEOD was closely related to perinatal infection, such as fever, gestational vaginitis, gestational bacteriuria, MSAF, and chorioamnionitis. E. coli was cultured from $45.65 \%$ of mothers and $60.87 \%$ of mothers developed chorioamnionitis; this indicated that $E$. coli colonization or infection in the urogenital system of pregnant women can cause intrauterine infection [18]. In our study, the incidence of GDM in mothers with E. coli-EOD newborns was significantly higher than that in mothers with $E$. coli-LOD. GDM may affect the development of fetal thymus and immune system, which can induce excessive inflammatory reaction in newborn through innate immune response mediated by TLR5 or TLR1/2 [19, 20]. We found that the incidence of neonatal $E$. coli-LOD was associated with prematurity, low-birth-weight infants, and low breastfeeding rate; in addition, most of these cases suffered from nosocomial infection, which was consistent with a previous report [3]. The immature immune status of premature or low-birth-weight infants, the typically long hospital stay, and lack of breastfeeding render these infants more vulnerable to $E$. coli infection.

In our study, E. coli-EOD often manifested as pneumonia with the main clinical manifestations of tachypnea; these infants were prone to complications such as ARDS, septic shock, pulmonary hemorrhage, and PPHN. However, E. coli-LOD typically manifested as sepsis, with fever as the main symptom, which was consistent with the disease spectrum and complications caused by intrauterine infection and nosocomial infection. These findings are consistent with those of previous studies $[2,21]$. There was no significant difference in the incidence of purulent meningitis between the E. coli-EOD group and E. coli-LOD group, which was inconsistent with other reports [22, 23]. Previous studies have shown that E. coli containing polysaccharide capsule $\mathrm{K} 1$ antigen has antiphagocytotic, anti-antibody and complement functions, leading to strong virulence and pathogenicity; thus, it is more likely to cause purulent meningitis [22]. E. coli carrying the einv virulence gene easily cause bloodstreamrelated infection, while CNF1 and CNF2 virulence genes may be closely related to the severity of lung damage and multiple organ damage [24]. Therefore, the difference of disease spectrum and complications in E. coliEOD and E. coli-LOD may be caused by different virulence genes carried by $E$. coli [25].

Characterization of the drug sensitivity profile of local E. coli strains is a key imperative since antibiotic therapy is the mainstay of treatment for $E$. coli invasive infection. In our study, the sensitivity rate of $E$. coli to ampicillin and piperacillin was as low as $23.49-28.79 \%$, while the sensitivity rates to cephalosporins other than ceftazidime were also low, especially in ESBL-positive E. coli. E. coli strains were found to be highly sensitive to compound preparations including $\beta$-lactamase inhibitor; in addition, no carbapenem- or amikacin-resistant strains were found in our study population. The above results were consistent with most previous reports [26, 27]. The sensitivity rates for quinolones and sulfonamides were approximately 70 and $50 \%$, respectively, which was significantly lower than that in a previous report [28]. The difference of antibiotic sensitivity to $E$. coli strains may be related to regional differences, and differences with respect to detection methods and antibiotic use habits. Interestingly, our study showed that the antimicrobial sensitivity of $E$. coli strains causing colonization was generally lower than that of invasive infection strains, including a significant difference with respect to the sensitivity to cephalosporins. This was because most bacterial colonization represented the surviving bacteria after overuse of antibiotics, while the invasive infection strains were mostly mediated by 
virulence factors. Therefore, antibiotics containing $\beta$ lactamase inhibitors such as piperacillin/tazobactam should be the first-choice treatment for $E$. coli invasive infection in Xiamen, China. Carbapenems such as meropenem should be considered only when the therapeutic effect is poor.

The widespread use of broad-spectrum antibiotics, especially the abuse of third-generation cephalosporins, is the main reason for the increase of ESBL producing strains. The mechanism of drug resistance of ESBLpositive E. coli strains is drug-induced target gene mutation; in addition, plasmid-mediated transmission among different strains leads to wide spread of drug-resistant strains [29]. In our study, the detection rates of ESBL in E. coli-EOD and E. coli-LOD groups were 25.76 and $32.14 \%$, respectively. These figures were significantly lower than those reported in other regions of China (45.4\%) and in studies conducted overseas (53\%) [29, 30]. This is likely attributable to less frequent use of cephalosporins in the neonatal department of our hospital, more intensive monitoring of bacterial resistance, and to the regional differences. In our study, the ESBLpositivity rate in E. coli-LOD was higher, and most of the cases were premature infants or low-birth-weight infants with nosocomial infection. The risk factors for occurrence of multi-drug resistant strains were premature delivery, low birth weight, invasive operation, and prolonged hospital stay. Therefore, premature or low-birthweight infants with long hospitalization stay should be considered at high risk of ESBL-positive $E$. coli invasive infection.

Some limitations of our study should be acknowledged. This was a single-center study, and we did not investigate the serotype and distribution of virulence genes of $E$. coli. Larger multi-center studies involving in-depth exploration at the level of molecular genotype are required for a more comprehensive analysis of invasive $E$. coli infection.

\section{Conclusion}

Our findings suggest that $E$. coli is an important causative pathogen of neonatal invasive infection in Xiamen, China. The clinical manifestations and the disease spectrum of neonatal E. coli-EOD were different from those of E. coli-LOD. The occurrence of E. coli-EOD was mostly related to perinatal factors, while E. coli-LOD was mostly related to acquired infection, especially nosocomial infection. Compound preparations containing $\beta$ lactamase inhibitor or carbapenems should be preferred for the treatment of neonatal $E$. coli invasive infection, especially for the ESBL-positive strains. This study provided epidemiological data pertaining to $E$. coli for further in-depth study of serotypes and genotypes, drug resistance genes, and virulence genes.

\section{Abbreviations}

E. coli: Escherichia coli; EOD: Early onset disease; LOD: Late onset disease; NICU: Neonatal intensive care unit; LBs: Live births; NAs: Neonatal admissions; ESBL: Extended spectrum $\beta$-lactamase; PROM: Premature rupture of membranes; MSAF: Meconium-stained amniotic fluid; GDM: Gestational diabetes mellitus; CLSI: Clinical and Laboratory Standards Institute; ARDS: Acute respiratory distress syndrome; PPHN: Persistent pulmonary hypertension of the newborn; NEC: Necrotizing enterocolitis; SD: Standard deviation; IQR: Interquartile range; UVC: Umbilical vein catheterization; PICC: Peripherally inserted central catheter

\section{Acknowledgements \\ We would like to thank all staff members for participation in and contribution to this study. We also thank the study participants for providing the samples.}

\section{Authors' contributions}

XZL conceptualized and designed the study, reviewed and revised the manuscript; JDL and YZ performed data analyses, literature search, and wrote the manuscript; LXT designed the data collection instruments, collected data; and all authors read and approved the final manuscript.

\section{Funding}

This work was supported by the 2017 Xiamen Science and Technology Planning Project (3502Z20171006). The authors declare that they have no financial relationship with the organization that sponsored the research, and the funding body was not involved in study design, data collection, analysis, or writing of the study.

\section{Availability of data and materials}

The datasets generated and analyzed during the current study are available from the corresponding author on reasonable request.

\section{Declarations}

\section{Ethics approval and consent to participate}

This study was approved by the Women and Children's Hospital, School of Medicine, Xiamen University. Oral consent was obtained from participants' parents, and demographics (omitted the participants and their mother's name) and clinical records were collected according to the verbal consent procedure. The verbal consent procedure was approved by the Institutional Review Board at our hospital.

\section{Consent for publication}

Not applicable.

\section{Competing interests}

The authors declare that they have no competing interests.

Received: 19 December 2020 Accepted: 10 March 2021 Published online: 23 March 2021

\section{References}

1. Liu L, Oza S, Hogan D, Chu Y, Perin J, Zhu J, Lawn JE, Cousens S, Mathers C, Black RE. Global, regional, and national causes of under-5 mortality in 200015: an updated systematic analysis with implications for the sustainable development goals. Lancet. 2016;388(10063):3027-35. https://doi.org/10.101 6/S0140-6736(16)31593-8.

2. Okomo U, Akpalu ENK, Le Doare K, Roca A, Cousens S, Jarde A, et al. Aetiology of invasive bacterial infection and antimicrobial resistance in neonates in sub-Saharan Africa: a systematic review and meta-analysis in line with the STROBE-NI reporting guidelines. Lancet Infect Dis. 2019;19(11): 1219-34. https://doi.org/10.1016/S1473-3099(19)30414-1.

3. Cailes B, Kortsalioudaki C, Buttery J, Pattnayak S, Greenough A, Matthes J, Bedford Russell A, Kennea N, Heath PT, neonIN network. Epidemiology of UK neonatal infections: the neonIN infection surveillance network. Arch Dis Child Fetal Neonatal Ed. 2018;103(6):F547-53. https://doi.org/10.1136/a rchdischild-2017-313203.

4. Shane AL, Sánchez PJ, Stoll BJ. Neonatal sepsis. Lancet. 2017;390(10104): 1770-80. https://doi.org/10.1016/S0140-6736(17)31002-4. 
5. Berardi A, Sforza F, Baroni L, Spada C, Ambretti S, Biasucci G, Bolognesi S, Capretti M, Carretto E, Ciccia M, Lanari M, Pedna MF, Rizzo V, Venturelli C, Tzialla C, Lucaccioni L, Reggiani MLB. Epidemiology and complications of late-onset sepsis: an Italian area-based study. PLoS One. 2019;14(11): e0225407. https://doi.org/10.1371/journal.pone.0225407.

6. Jiang S, Hong L, Gai J, Shi J, Yang Y, Lee SK, Cao Y, REIN-EPIQ Study Group. Early-onset Sepsis among preterm neonates in China, 2015 to 2018. Pediatr Infect Dis J. 2019;38(12):1236-41. https://doi.org/10.1097/INF. 0000000000002492.

7. Zhao Z, Yu JL, Zhang HB, Li JH, Li ZK. Five-year multicenter study of clinical tests of neonatal purulent meningitis. Clin Pediatr (Phila). 2018;57(4):389-97. https://doi.org/10.1177/0009922817728699.

8. Shao XM, Ye HM, Qiu XS. Practical Neonatology. 5th ed. Beijing: People's Medical Publishing House; 2019.

9. Neonatology Group of Pediatrics Branch of Chinese Medical Association. Expert consensus on the diagnosis and treatment of neonatal sepsis (2019 edition). Chin J Pediatr. 2019:57(4):252-7.

10. De Luca D, van Kaam AH, Tingay DG, Courtney SE, Danhaive O, Carnielli VP, et al. The Montreux definition of neonatal ARDS: biological and clinical background behind the description of a new entity. Lancet Respir Med. 2017;5(8):657-66. https://doi.org/10.1016/S2213-2600(17)30214-X.

11. Rhodes A, Evans LE, Alhazzani W, Levy MM, Antonelli M, Ferrer R, Kumar A, Sevransky JE, Sprung CL, Nunnally ME, Rochwerg B, Rubenfeld GD, Angus DC, Annane D, Beale RJ, Bellinghan GJ, Bernard GR, Chiche JD, Coopersmith C, de Backer DP, French CJ, Fujishima S, Gerlach H, Hidalgo JL, Hollenberg SM, Jones AE, Karnad DR, Kleinpell RM, Koh Y, Lisboa TC, Machado FR, Marini JJ, Marshall JC, Mazuski JE, McIntyre LA, McLean AS, Mehta S, Moreno RP, Myburgh J, Navalesi P, Nishida O, Osborn TM, Perner A, Plunkett CM, Ranieri M, Schorr CA, Seckel MA, Seymour CW, Shieh L, Shukri KA, Simpson SQ, Singer $M$, Thompson BT, Townsend SR, van der Poll T, Vincent JL, Wiersinga WJ, Zimmerman JL, Dellinger RP. Surviving Sepsis campaign: international guidelines for Management of Sepsis and Septic Shock: 2016. Intensive Care Med. 2017;43(3):304-77. https://doi.org/10.1007/s00134-017-4 683-6.

12. Abman SH, Hansmann G, Archer SL, Ivy DD, Adatia I, Chung WK, Hanna BD, Rosenzweig EB, Raj JU, Cornfield D, Stenmark KR, Steinhorn R, Thébaud B, Fineman JR, Kuehne T, Feinstein JA, Friedberg MK, Earing M, Barst RJ, Keller RL, Kinsella JP, Mullen M, Deterding R, Kulik T, Mallory G, Humpl T, Wessel $\mathrm{DL}$, American Heart Association Council on Cardiopulmonary, Critical Care, Perioperative and Resuscitation; Council on Clinical Cardiology; Council on Cardiovascular Disease in the Young; Council on Cardiovascular Radiology and Intervention; Council on Cardiovascular Surgery and Anesthesia; and the American Thoracic Society. Pediatric pulmonary hypertension: guidelines from the American Heart Association and American Thoracic Society. Circulation. 2015;132(21):2037-99. https://doi.org/10.1161/CIR. 0000000000000329

13. Mendoza-Palomar N, Balasch-Carulla M, González-Di Lauro S, Céspedes MC, Andreu A, Frick MA, et al. Escherichia coli early-onset sepsis: trends over two decades. Eur J Pediatr. 2017;176(9):1227-34. https://doi.org/10.1007/s00431017-2975-z.

14. Glikman D, Curiel N, Glatman-Freedman A, Megged O, Youngster I, Marom R, Lavie K, Smolkin T, Troitzky M, Stein M, the EOS Israeli study group, Stein M, Glikman D, Curiel N, Glatman-Freedman A, Megged O, Eventov-Fiedman S, Keller N, Kriger O, Somekh E, Tasher D, Gottesman G, Guri A, AshkenaziHoffnung L, Ben-Zvi H, Youngster I, Herzlich J, Schindler Y, Marom R, Rubinstein U, Midlij E, Miron D, Damouni R, Kassis I, Nimri-Atrash N, Freiman S, Lavie K, Smolkin T, Melamed R, Troitzky M, Sayag A. Nationwide epidemiology of early-onset sepsis in Israel 2010-2015, time to re-evaluate empiric treatment. Acta Paediatr. 2019;108(12):2192-8. https://doi.org/1 $0.1111 / a p a .14889$.

15. Investigators of the Delhi Neonatal Infection Study (DeNIS) collaboration. Characterisation and antimicrobial resistance of sepsis pathogens in neonates born in tertiary care centres in Delhi, India: a cohort study. Lancet Glob Health. 2016;4(10):e752-60. https://doi.org/10.1016/\$2214-109X(16)3 0148-6.

16. Lin MC, Chiu NC, Chi H, Ho CS, Huang FY. Evolving trends of neonatal and childhood bacterial meningitis in northern Taiwan. J Microbiol Immunol Infect. 2015;48(3):296-301. https://doi.org/10.1016/j.jmii.2013.08.012.

17. Zhu $Y$, Lin $Y$, Jidong $L$, Lin $X$. The effect of prenatal antibiotics on the clinical features and pathogen distribution of neonatal early-onset sepsis. Chin J Perinat Med. 2017;20(1):21-6.
18. Peng CC, Chang JH, Lin HY, Cheng PJ, Su BH. Intrauterine inflammation, infection, or both (triple I): a new concept for chorioamnionitis. Pediatr Neonatol. 2018;59(3):231-7. https://doi.org/10.1016/j.pedneo.2017.09.001.

19. Warncke K, Lickert R, Eitel S, Gloning KP, Bonifacio E, Sedlmeier EM, Becker P, Knoop J, Beyerlein A, Ziegler AG. Thymus growth and fetal immune responses in diabetic pregnancies. Horm Metab Res. 2017:49(11):892-8. https://doi.org/10.1055/s-0043-120671.

20. Yanai S, Tokuhara D, Tachibana D, Saito M, Sakashita Y, Shintaku H, Koyama M. Diabetic pregnancy activates the innate immune response through TLR5 or TLR1/2 on neonatal monocyte. J Reprod Immunol. 2016;117:17-23. https://doi.org/10.1016/j.ji.2016.06.007.

21. Jang J, Hur HG, Sadowsky MJ, Byappanahalli MN, Yan T, Ishii S. Environmental Escherichia coli: ecology and public health implications-a review. J Appl Microbiol. 2017;123(3):570-81. https://doi.org/10.1111/jam.134 68.

22. Barichello T, Fagundes GD, Generoso JS, Elias SG, Simões LR, Teixeira AL. Pathophysiology of neonatal acute bacterial meningitis. J Med Microbiol. 2013;62(Pt 12):1781-9. https://doi.org/10.1099/jmm.0.059840-0.

23. Kasanmoentalib ES, Brouwer MC, van de Beek D. Update on bacterial meningitis: epidemiology, trials and genetic association studies. Curr Opin Neurol. 2013;26(3):282-8. https://doi.org/10.1097/WCO.0b013e328360415c.

24. Shen Y, Wang Y, Kaihu Y, Gao W, Yijun D, Wu D, et al. Study on virulence factors of Escherichia coli isolates in hospitalized newborns. Chin J Evid Based Pediatr. 2015;10(1):62-5.

25. Wijetunge DS, Gongati S, DebRoy C, Kim KS, Couraud PO, Romero IA, et al. Characterizing the pathotype of neonatal meningitis causing Escherichia coli (NMEC). BMC Microbiol. 2015;15(1):211. https://doi.org/10.1186/s12866015-0547-9.

26. Li X, Ding X, Shi P, Zhu Y, Huang Y, Li Q, Lu J, Li Z, Zhu L. Clinical features and antimicrobial susceptibility profiles of culture-proven neonatal sepsis in a tertiary children's hospital, 2013 to 2017. Medicine (Baltimore). 2019;98(12): e14686. https://doi.org/10.1097/MD.0000000000014686.

27. Cole BK, Ilikj M, McCloskey CB, Chavez-Bueno S. Antibiotic resistance and molecular characterization of bacteremia Escherichia coli isolates from newborns in the United States. PLoS One. 2019;14(7):e0219352. https://doi. org/10.1371/journal.pone.0219352.

28. Lee DS, Lee SJ, Choe HS. Community-acquired urinary tract infection by Escherichia coli in the era of antibiotic resistance. Biomed Res Int. 2018;2018: 7656752.

29. Hertz FB, Jansåker F, Okon KO, Abdulmumin IS, Onah JO, Ladan J, Knudsen JD. ESBL-production in Escherichia coli and Klebsiella pneumoniae isolates from Nigeria. Microbiologyopen. 2019;8(9):e00816. https://doi.org/10.1002/ mbo3.816.

30. Haiying LI, Baowei DONG, Yahong BAI. Drug resistance of Escherichia coli from 2008 to 2010. Chin J Nosocomiol. 2013;23(3):673-5.

\section{Publisher's Note}

Springer Nature remains neutral with regard to jurisdictional claims in published maps and institutional affiliations.

Ready to submit your research? Choose BMC and benefit from:

- fast, convenient online submission

- thorough peer review by experienced researchers in your field

- rapid publication on acceptance

- support for research data, including large and complex data types

- gold Open Access which fosters wider collaboration and increased citations

- maximum visibility for your research: over $100 \mathrm{M}$ website views per year

At BMC, research is always in progress.

Learn more biomedcentral.com/submissions 